\title{
Obstetric Fistula and Common Peroneal Nerve Palsy in a Rural Based Women: A Case Report
}

Suchanda Das ${ }^{1 *}$

Rokeya Begum'

Bidhan Roy Chowdhury ${ }^{2}$

'Department of Obstetrics and Gynaecology Chittagong Medical College, Chittagong, Bangladesh.

${ }^{2}$ Department of Paediatrics University of Science \& Technology Chittagong (USTC) Chittagong, Bangladesh.
*Correspondence to:

\section{Dr. Suchanda Das}

Junior Consultant

Department of Obstetrics and Gynaecology

Chittagong Medical College, Chittagong, Bangladesh. Mobile : 01817738309

Email: drsuchandadas@yahoo.com

\begin{abstract}
Neglected obstructed labor is a major cause of both maternal and newborn morbidity and mortality. By far the most severe and distressing long term morbidity following obstructed labor is obstetric fistula i.e. Vesicovaginal fistula. In developing countries fistula is commonly the result of prolonged obstructed labor. A18 year old primi gravida was admitted in the labor ward with the involuntary passage of stool and urine and unable to walk after 15 days of her home delivery. Temporary colostomy was done. Patient was on regular physiotherapy for prolonged time and she was responded slowly. There was a plan for repair of Vesicovaginal and Rectovaginal fistula. Obstructed labor complex is completely preventable if high quality basic and comprehensive health services are available to all.
\end{abstract}

Key word: Foot drop; Obstructive fistula; Peroneal nerve palsy; Rectovaginal fistula; Vesicovaginal fistula.

\section{INTRODUCTION}

One of the most devastating consequences of prolonged obstructed labor is obstetric fistula. Now a days it is historical issue in developed countries but still prevalent in developing countries ${ }^{1}$. In prolonged obstructed labor, there is peroneal nerve injury which causes leg weakness and foot drop ${ }^{2} .40 \%$ percent of our total populations live below the poverty line. Here, the average age of marriage is 18 years and the age of first child birth is 18.7 years. 53.8 are the contraceptive prevalence rate ${ }^{3}$.

Motherhood has a very important cultural connotation in the lives of young women; early child birth is very common in Bangladesh. Due to low status of women their access to reproductive health care is also limited ${ }^{3}$. Many research finding have portrayed the links between the educational level of women and their general access to reproductive health services. It has been established that higher educational level are associated with increased level of reproductive health services. The literacy rate of women in Bangladesh is low which is an additional factor contributing to the low use of reproductive health services ${ }^{1}$.

At the grass root level, though there is introduction of "Essential Service Packages" in the recent year, the low utilization rate indicate that much more setting up one stop service ${ }^{3}$.

Obstructed labor complex is completely preventable if high quality basic and comprehensive maternal health services are available to all. The plight of fistula patients must be seriously considered if the efforts to meet the Millennium Development Goals (MDGs) are to be effective ${ }^{1}$. 


\section{CASE REPORT}

Mrs. "B", A 18 year old house wife of poor socio-economic status hailing from Teknuf, Cox's-Bazar, was admitted in the labor ward of Chittagong Medical College Hospital on 24 February, 2013 at 1-00 am. She came to hospital after three days of her labor pain and rupture membrane. Just after reaching hospital she was delivered a dead fetus vaginally. Immediately after delivery she noticed that she was unable to walk. After 15 days of her vaginal delivery she developed involuntary passage of stool and urine.

On examination she was moderately anemic and malnourished. Her temperature was $101^{\circ} \mathrm{F}$, pulse 104 beats per minutes, BP $100 / 60 \mathrm{~mm}$ of $\mathrm{Hg}$. Per abdominal examination revealed sub involution of uterus. Per vaginal examination revealed $5 \mathrm{~cm}$ fistula at bladder base and $2 \mathrm{~cm}$ fistula at posterior wall of upper part of vagina. Neurological examination revealed there was gross wasting of muscles of both legs. Injury to the common peroneal nerve results in paresthesia on the dorsa of the feet and lateral calves, as well as foot drop. After improvement of her general condition, correction of anemia, subsidence of infection by conservative treatment, temporary colostomy was done on 5 March 2013. Later on a Surgeon and Urologist were consulted and a plan was developed for repair of Vesicovaginal \& Rectovaginal fistula after 3 months. Meanwhile, she was practicing regular exercise as per advice of a physiotherapist. After regular exercise she was able to walk \& there was improvement of her neurological symptoms.

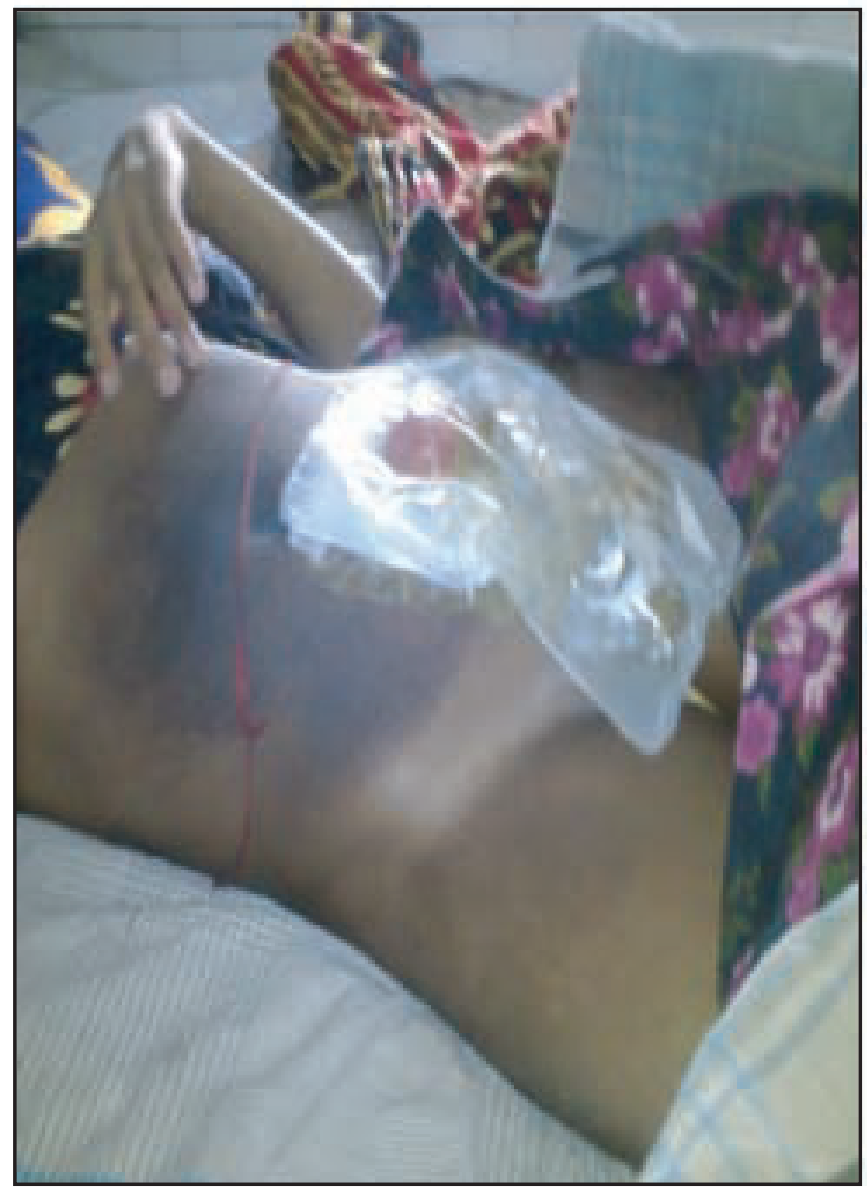

Figure 1 : Patients colostomy was done

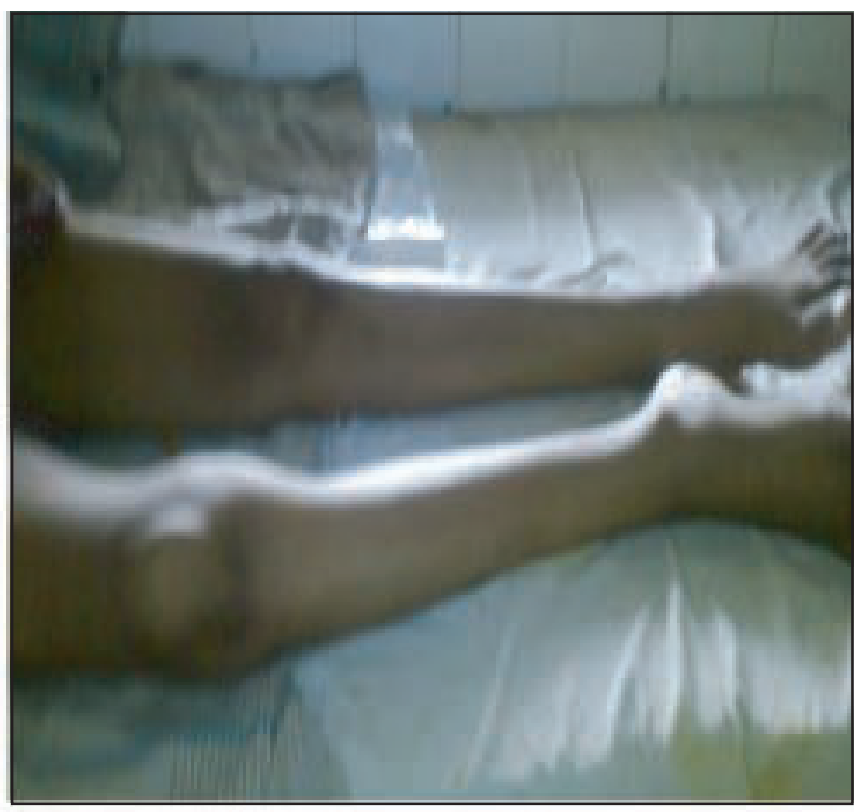

Figure 2 : Patients Peroneal nerve injury causing Atropy of legs

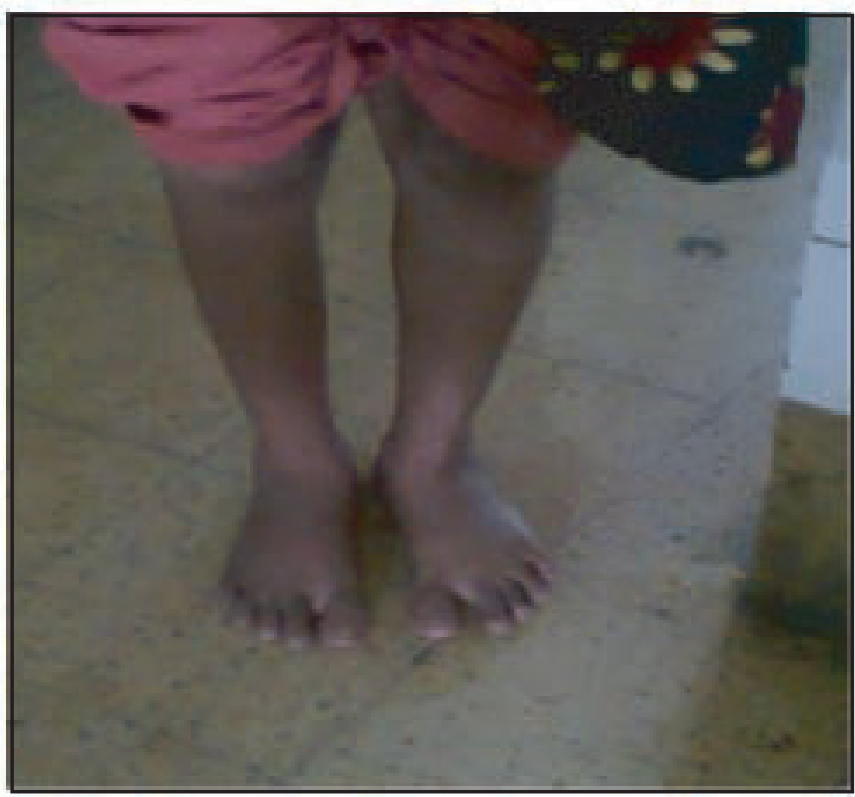

Figure 3 : Patient has improved after 2 month of physiotherapy

\section{DISCUSSION}

A Vesicovaginal Fistula (VVF) is an abnormal opening between the vagina and the urinary bladder, through which urine continually leaks continuously. Naturally, VVF makes the patient embarrassed as they are unable to control their bodily functions, constantly wet and smell. Thus, VVF have a profound effect on the patient's emotional well-being due to social distress because of persistent leakage of urine. This may be further complicated by recurring infections, infertility, and damage to the vaginal tissue that makes sexual activity impossible. In the developing world countries, the true incidence of VVFs is unknown, as many patients with this condition are suffering in silence and isolation. 70-90\% of women with fistula in India and Pakistan are divorced or abandoned from society ${ }^{4}$. 
In the past, obstetric complications like prolonged obstructed labor, coupled with a lack of medical attention, were more common causes of VVF 5 .

Obstructed labor injury complex like VVF, RVF, \& foot drop, has a profound effect on patients emotional well being. It results in a social stigma apart from medical sequel. The solution to the fistula problem will ultimately comes from the provision of emergency obstetric care services and for Neurological symptoms (i.e. foot drop, muscle wasting) the role of physiotherapy and nutritional status cannot be ignored. Continuous urinary and fecal leakage creates social and psychological stress to the affected women. Timing and methods of surgery are subjected to varied opinion and dependent of precise characteristics of each fistula. In female due to close association between genital and urinary tract, there is more chance of urinary tract injury after difficult and traumatic delivery ${ }^{5}$. So the important leading cause of VVF is obstetric case and from the scenarios we can realize that proper intra -natal care is still not available especially at rural setting ${ }^{6}$.

\section{CONCLUSION}

Obstetricians and Gynecologists must lead the way to liberate young women who are already on the road to maternal death or to developing obstetric fistula. The calamities which these young girls and mothers are facing must inspire us to do this enormous task of preventing the injury, treating the affected, and searching for the best approaches for both prevention and treatment. Fistula patients are the living indicators of poor maternal health care and failed health systems, but they are largely ignored by the world.

\section{DISCLOSURE}

All the authors declared no competing interest.

\section{REFERENCES}

1. Mulu Muleta, Obstetric Fistula in Developing Countries: A Review Article Obstetrician-Gynecologist, Addis Ababa Fistula Hospital, Addis Ababa Ethiopia, J Obstet Gynaecol Can. 2006;28(11):962-966.

2. K. Waaldijk \& Dr T. E. Elkins; The obstetric fistula and peroneal nerve injury: An analysis of 947 consecutive patients; International Urogynecology Journal. 1994; 5 (1) : 12-14.

3. Nashid Kamal Waiz, Marlam Faruqul, Anowara Bagum, Nazneen Sultana, Sukanta Sarker, Abu Jamil Faisel; SITUATION ANALYSIS OF OBSTETRIC FISTULA IN BANGLADESH, Report; EngenderHealth Bangladesh country office. 2003;8.

4. Mumtaz Ahmad, Mohammad Alam and Jehan Ara; Management of Vesicovaginal Fistula; Ann. Pak. Inst. Med. Sci. 2012; 8(1): 11-13.

5. Choudhuri Dolly, Goswami Sebanti, Adhikari Sudhir, Sanghamita Mamtaz; Analysis of vesicovaginal fistula in Eden Hospitala 10 year study; J Obstet Gynaecol India. 2007;57(2) : 139-141.

6. Pal Amitava, Ray Kumar Prasanta, Bhadra Debjani, Lahiri Kumar Tapan; Surgical repair of Genital Fistulae- Analysis of 62 cases in a tertiary Hospital; J Obstet Gynaecol India. 2010;60(5):424-428. 